\title{
Comfort in Labor and Midwifery Art
}

\author{
Kerri Durnell Schuiling, Carolyn M. Sampselle
}

Purpose: To examine the phenomenon of comfort in the context of childbirth. Enhancement of comfort for laboring women is a valued outcome of nursing and midwifery care. Interventions that increase comfort during labor support a woman's effort to participate more fully in the birth thereby keeping her more aware of her body, emotions, and experience.

Organizing construct: The concept of comfort is analyzed and defined in the context of laboring women. Comfort studied from a feminist perspective is suggested.

Sources: A literature review of nursing, midwifery, and medical texts from the 1920 s to 1998 provides information about labor, pain in labor, and goals of providers caring for laboring women. Research articles focusing on comfort are identified as they relate to the concept of comfort in labor. Writings of contemporary feminist authors provided the ideas for designing the study of comfort from a feminist perspective.

Methods: To develop a theory of comfort during labor, early nursing and midwifery texts were searched to identify goals of care. The meaning of comfort was analyzed from the early 1920s to the present by concept analysis. Validation of findings was sought from publications on comfort research.

Findings: Comfort can exist in spite of great pain and nurses and midwives may be able to assist laboring women to achieve a level of comfort during labor. Intervening to promote the comfort of laboring women can empower these women during birthing.

Conclusions: For clinicians caring for birthing women, particularly midwives, promotion of comfort is a high priority. Increasing comfort can redefine the meaning of pain in childbirth. Increasing comfort may create a decreased need for medical interventions and lower costs.

Image: Journal of Nursing Scholarship, 1999; 31:1, 77-81. (1999 Sigma Theta Tau International.

[Key words: comfort; childbirth; labor]

C omfort and labor may seem to be paradoxical. In fact, the fast growing use of epidural anesthesia suggests that obliteration of pain during labor is often preferred. However, the absence of pain is neither necessary nor sufficient for one to experience comfort. Nurse-midwifery advocates self-determination and active participation by women in all aspects of their care (American College of Nurse-Midwives [ACNM], 1983). More generally, promoting comfort by encouraging women to use self-identified comfort measures is a common component of midwifery practice. We assume that nurses can provide comfort in the presence of pain, that pain does not have to be eliminated for women to be comforted, and that comforting can diminish pain.

\section{Review}

\section{Labor Pain}

Pain in childbirth has received much attention in the literature (Cahill, 1989; Fridh, Kopare, Gaston-Johansson, \& Norvelle, 1988; Kelpin, 1984; Lowe, 1989, 1991, 1996; Mander, 1992;
Stampone, 1990; Yerby, 1996; Youngstrom, Baker \& Miller, 1996). Labor pain, like all pain, is both physiologic and psychologic. Alleviation of pain has been identified as a source of comfort and support to women in labor (Hodnett, 1996). Pain can modify and affect the level of comfort a woman achieves during childbirth. Weber (1996) identifies recognition and treatment of pain and discomfort as critical elements of obstetric care.

The pain of normal childbirth differs from other types of pain because it is not pathologic (Lowe, 1996). In uncomplicated childbirth, pain is part of a normal physiologic process and is evidence of accomplishing a desired outcome, the birth of an infant.

Kerri Durnell Schuiling, MSN, WHNP, CNM, Kappa \& Rho, Acting Education Director, FSMFN/CNEP, and Pre-doctoral Candidate, University of Michigan School of Nursing; Carolyn M. Sampselle, RNC, PhD, FAAN, Rho, Associate Professor-Nursing, OB/GYN, Women' Studies, University of Michigan, Ann Arbor, MI. The authors thank the members of the 1996 University of Michigan seminar, "Transforming Women's Health," for their comments and critique; also, Professor Karen Stein for her critique of the original concept. Correspondence to Ms. Schuiling, 339 E. Ridge, Marquette, MI 49855. E-mail: kschuil@midwives.org

Accepted for publication February 18, 1998. 
A woman's perception of pain depends on psychologic and physiologic factors (Lowe, 1996; Yerby, 1996). The primary physiologic force during labor is uterine contractions (Varney, 1997). Pressure and contraction of the uterus combined with application of the fetal presenting part on the cervix cause pain by increasing the release of prostaglandins and other substances (Yerby, 1996). Labor contractions are usually mild and irregular at the onset, building gradually in intensity and duration (Yerby, 1996). This gradual increase in strength and intensity enables a woman to identify and adapt coping mechanisms to enable her to be an active participant in birthing.

Pain has a protective function when it signals tissue damage and stimulates behavior that preserves tissue integrity. The inflammatory response occurs after tissue injury inducing a cascade of nonspecific events (Kuby, 1994). Important mediators of the inflammation response are kinins. Kinins are small peptides activated during tissue injury. Bradykinins stimulate pain receptors in the skin (Kuby, 1994). This effect probably serves a protective role because pain signifies an injured area needs protection. An example of this is observable during the active phase of labor when fetal descent occurs and during the second stage as the infant is born. A woman who perceives her body's response during a bearing-down effort is able to adjust her pushing. This alteration in response to biofeedback can minimize tissue damage and be protective of perineal tissues by decreasing the potential for stretch and disruption (Sampselle \& Hines, in press). A woman anesthetized by an epidural anesthetic does not have feel the nuances of pain in relation to pressure and is typically instructed about pushing efforts. In the absence of biofeedback, she is unable to make protective adjustments.

Studies of pregnant women identify neuropeptides (betaendorphins and enkephalkins) which may modulate pain during labor allowing the woman to work with the process (Cahill, 1989). Blunting perception of pain, as opposed to obliterating pain, enables a woman to interpret and react to negative stimuli. This allows for continued self-assessment of well being.

Lowe (1989) found maternal confidence to be a crucial variable in the explanation of women's perception of active labor pain. Lowe suggests maternal confidence may act independently in reducing pain and identifies questions for further study such as: What variables might contribute to a woman's confidence in her ability to handle labor? Which variables are amenable to intervention?

Comfort and comfort care measures appear to be variables that would increase maternal confidence. Women should be encouraged to identify measures that provide comfort during times of stress or pain. Interventions such as music, backrubs, warm baths, and the presence of a significant other may provide comfort and promote confidence and strength empowering laboring women to master the birth process. Nonpharmacologic interventions may be used instead of - or as an adjunct to-narcotics or epidural anesthesia. When nonpharmacologic and pharmacologic methods of pain relief are combined, the total dosage of narcotics needed to give pain relief may be less (Simkin, 1995).

How women express, manage, cope, and work with labor pain is individual and dependent on a variety of factors. Lowe (1996) states:

The experience of pain during labor is not a simple reflection of the physiologic processes of parturition. Instead, labor pain is the result of a complex and subjective interaction of multiple physiologic and psychosocial factors on a woman's individual interpretation of labor stimuli. (p.82)
Pain of childbirth may be perceived as a strengthening event, a challenge to be met, or as noxious stimuli. How a woman defines her labor pain affects her management of it and her perception of the birth event. Mastery of the process can lead to increased selfesteem and personal strength (Lowe, 1996). Davenport-Slack and Boylan (1974) investigated the concept of control and childbirth satisfaction and concluded that women who desire and are given the opportunity to be active participants in birthing have a more satisfying experience than those who rely on physicians and drugs.

\section{Comfort}

Finding and maintaining comfort is common to all people. Providing services that are comfort promoting is also common. Many people quickly identify loss of comfort and work diligently to restore it. During labor, a person might need assistance to regain comfort.

Comfort is frequently described in the nursing literature as a goal of nursing care. Bertha Harmer (1924) notes in her Text-book of the Principles and Practice of Nursing, that nursing care is concerned with providing a "comfortable environment" and that personal care of patients includes making them "feel comfortable" (p.4). Giving comfort is described as an aspect of the nurse's duty (Van Blarcom, 1953). Comfort has also been described as "the most important nursing action in the provision of nursing care for the sick" (Morse, 1983, p.6).

Providing comfort is commonly referred to as nursing art; but definition and operationalization of the idea of comfort is unclear. Comfort has only recently begun to be defined in the literature (Jacox, 1989; Kolcaba, 1991, 1994; Morse, 1983; Morse, Bottorff, \& Hutchinson, 1994, 1995). Most often comfort is described in relation to factors that deprive one of comfort such as fatigue, nausea, and pain (Funk, Tornquist, Champagne, Copp, \& Wiese, 1989). Although Jacox (1989) identifies pain, nausea, and fatigue as components of comfort, these entities are actually components of discomfort because they deprive one of comfort.

Comfort is described as related to corporeality. A phenomenologic study done by Morse and colleagues (1995) involved inviting 36 patients with life-threatening illnesses to "tell their stories." Eight themes relating to the discomforts of the body in illness or injury emerged: the diseased body; the disobedient body; the vulnerable body; the violated body; the enduring body; the resigned body; the deceiving body; and the betraying body. However, this schema is derived from an illness focus rather than a health and wellness focus.

A clearer definition of comfort related to theories of health and wellness has been developed by Kolcaba (1991, 1994, 1995b). Three technical senses of comfort - ease, relief, and transcendence-were derived from etymologic and conceptual analyses. Four contextsphysical, social, psychospiritual, and environmental-were synthesized from the literature on holism. Juxtaposing these, a taxonomic structure consisting of 12 elements was created as the domain of patient comfort (Kolcaba, 1991). Comfort in labor fits into this structure with respect to transcendence from physical pain. Paterson and Zderad (1976) state that comfort occurs when patients control and plan their destiny within a particular time and situation. Transcendence differs from other aspects of comfort because it necessitates patients' participation and is dependant on their performance and potential to overcome pain or disability (Kolcaba, 1991). 
Cameron (1993), studying comfort of hospitalized medical surgical patients, described a process of integrative balancing enabling patients to achieve a higher level of comfort on their own. Integrative balancing was observed in all clients and was an active process. Patients were able to act on information received from monitoring their internal and external environments. This finding can be applicable to studying comfort in labor. For example, it is reasonable to hypothesize that continued ability to self-monitor increases self-confidence, provides a sense of security, and reassures the birthing woman, thereby increasing her potential for comfort.

Other scholars recognize comfort as both process and a product (Cameron, 1993; Gropper, 1992; Kolcaba, 1995a, 1995b; Walters, 1994). Gropper (1992) describes comfort as an individualized patient goal assisting a person to achieve a state of health. Walters (1994) did a qualitative study of the comforting role of critical care nurses. A phenomenologic definition was that the comforting role includes providing support, relieving pain and anxiety, communicating, using touch, and comforting family and friends.

An ethnoscientific analysis of comfort identified comforting as having two main segregates, touching and talking (Morse, 1983). A third minor segregate, listening, was identified as used for "very stressed" people (Morse, 1983 p. 11). These researchers validate Kolcaba's (1995a, 1995b) proposition of "comfort care" as a process of comforting stimulated by the patient and caregiver's perception of comfort needs (Kolcaba 1995a, 1995b; Morse, 1983). The comforting process in these studies appears to be strengthening for the patient; coping mechanisms are enhanced. Comfort is thus identified as a desirable outcome of nursing care.

\section{Comfort during Labor}

Research reports about childbearing and enhancing comfort are scarce. In fact, research reports purported by title to be about comfort during childbirth are often about alleviation of pain during labor (Andrews \& Chrzanowski, 1990; Cogan, 1975). This may reflect a lack of recognition of the potential for comfort during a time commonly viewed as one of great travail. Just as health is much more than the mere absence of disease, so comfort may be experienced even in the presence of great pain.

Comfort may be the dominant perception during labor if comforting techniques that the woman identifies are provided during childbirth. Collins, McCoy, Sale, and Weber (1994) described comfort as experienced by substance-using and non-using postpartum women. The two groups were compared to determine if the characterization of comfort by each group is different. Little descriptive difference between the two groups of women was observed and it was concluded that comfort is more than absence of pain. Resolution of fatigue, satiation of hunger, easing of individual irritants, and relaxation were also important in providing a sense of comfort. A supportive presence and caring nursing approach were identified as the most helpful interventions (Collins et al., 1994).

Probably nowhere in midwifery care is the aspect of "promoting comfort" more evident than when caring for a woman in labor. Enhancing comfort may enable women to find the strength needed to work with nature during birth. In contrast, "medicalized" birthing, so predominant in the United States, alienates some women from themselves and their experience. Interventions that increase comfort during labor support a woman's effort to be an active participant in the birth, thereby keeping her "connected" to her body, emotions, and experience. Viewing promotion of comfort in this respect recognizes comfort as integral to the "art" of nurse-midwifery care.

Studies of comfort by other authors (Cameron, 1993; McIlveen \& Morse, 1995) point out that older definitions of comfort include strengthening as a critical attribute. The concept of comfort as strengthening during labor challenges the biomedical model dominant in obstetric care provided in the United States. Enhancing comfort may decrease the power inequity between a woman and her care provider. Comfort as strengthening provides a powerful paradigm shift in interpreting the meaning of pain in labor. The current dominant view, largely unquestioned, is that birthing pain is bad and should be eliminated.

In summary, researchers demonstrate that comfort conceptualized as a basic human need, a requisite for health, and an integral component of nursing and nurse-midwifery care has not been easy to define or describe. Whether comfort exists in labor, whether promoting comfort in labor is strengthening for a woman, whether it promotes her sense of mastery of the event and is empowering warrants further exploration.

\section{Definition of Comfort}

Based on the extant literature and clinical observation the following definition of comfort was developed.

The feeling of comfort is the expression of having met present or impending (perceived) needs or desires in three domains: body, mind, and spirit. It provides for feelings of relief, ease, security, well being, hope, and expectation.

Comfort is a state of being and a state of mind. The perception of comfort is individual, gendered, and multidimensional. It is relative to time, space, and magnitude.

Comfort arises from cognizance of met needs or desires in three interrelated domains, which make up the totality of a person (a) body, (b) mind and, (c) spirit. The needs or desires within each area can have dominance over those perceived in another domain, depending on a person's focus or interpretation of the unmet need or desire. Holistic comfort results when all needs or desires are met in each of these domains to the individual's sense of satisfaction.

Comfort in the corporeal (body) sense involves having met physical needs of hunger, thirst, air, and infirmity. It elicits feelings of relief from physical pain and provides for a sense of physical ease.

In the psychological (mind) domain, comfort involves peace of mind, feelings of security, and a freedom from anxiety or worry. The person feels a sense of contentedness.

Spiritual (soul, spirit) comfort feelings arise from a connected relationship with a higher power or authority by which one's beliefs assist with transcendence from physical or emotional pain or infirmity. In this domain, feelings of hope and expectation are most dominant.

The sense of "comfort" is dichotomous; it is present or absent and most noticeable when moving from a state of its presence or loss. Comfort once attained takes on magnitude. There are levels of comfort.

This definition allows for theorizing the existence of comfort in labor. Birthing women who are comforted during labor may be able to transcend their pain. They may experience a sense of strengthening 
just as injured children who are hurting are comforted and stop crying when hugged by their mother. Even in the absence of physical comfort, profound psychological and spiritual comfort may be experienced. Laboring women may be able to sense increased comfort psychologically and spiritually and transcend physical pain and give birth with need for less medical intervention.

\section{Future Research}

A research focus on comfort as an outcome of care during labor is feminist in that it includes more than just morbidity and mortality. Women are asked to give voice to their experience. Many women today give birth in male-dominated bureaucracies. Little social affirmation of a woman's power to give birth and little encouragement for her to give birth under her own power is evident despite the fact most women are capable.

Many women believe they are unable to give birth without receiving medication. Women accept as fact that pain should be obliterated. The belief persists that women are, in fact, unable to give birth under their own power.

Stewart (1994) provides an important feminist strategy for studying women's lives by urging us to look for what has been left out. Comfort in labor is not identified as a goal in the medical literature. A medical view of pain views is that it is pathologic. The canon of "pain as bad" leaves out the possibility of pain as protective. No consideration is given to the fact that comfort may exist despite pain. Pain and comfort in labor may be central to a woman's perception of mastery of the birth event. Comfort research identifies a woman's agency during the childbirth process. It has the potential to assist women to realize the power they possess. Regardless of whether or not pain medication is needed in labor, using comforting techniques may strengthen a woman and she may gain an appreciation of her capabilities.

If promoting comfort is strengthening and enables women to identify coping mechanisms allowing for greater participation and mastery of the birth event, comfort can then be identified as also promoting a safe and satisfying birth experience encompassing selfdetermination and health (Thompson, Oakley, Burke, Jay, \& Conklin, 1989). Defining the concept of comfort in labor and identifying those interventions which are comfort promoting could assist in elucidating and developing measures which would verify the presence of comfort and perhaps be physiologically quantifiable. Thus, the following research questions should be addressed:

1. Does comfort exist as a phenomenon in labor?

2. What are the components of comfort in the context of the childbirth, as identified by laboring women?

3. How do processes of care focusing on enhancing comfort affect womens' perception of the birth event?

4. If a woman in labor identifies comfort as being enhanced, does she use fewer medical interventions during labor and birth?

5. Does use of comfort measures provide for better physical outcomes especially as related to perineal tissues?

6. What are the biologic and physiologic markers of comfort which could quantify the physiologic effect of providing comfort?

\section{Conclusions}

The idea of comfort in the context of laboring women is of importance to researchers because it enables women to name what is important to them during birth and to potentially reconceptualize aspects of birthing. Comfort during labor deconstructs the biomedical model of the meaning of pain in labor. Research on comfort in labor can give credibility to women's voices through their own experience. Comfort research also has merit in allowing exploration of a phenomenon not previously explained in literature. Descriptions of its presence and its affective and physical qualities as experienced by laboring women has the potential to assist in identifying interventions that can be health promoting for mother and baby and cost-effective.

Midwifery care using nonpharmacologic interventions to enhance comfort in labor can have far-reaching effects. Supportive measures for laboring women can be individualized and perhaps be more effective. Cost-effectiveness through use of nonpharmacologic measures for promoting comfort is possible. Enhancing comfort during labor and documenting a positive effect can assist women to know their bodies and discover the strength they have within themselves. Adrienne Rich, Of Woman Born, (1976) contrasts the 20 th century woman's view of childbirth - which is fraught with ideas of severe pain, avoidance, and fear — with the following:

\footnotetext{
A woman preparing to swim the English Channel, or to climb high altitudes, is aware that her system will undergo stress, her courage will be tested, and her life may even be in danger; but despite the demands to be expected on her heart, her lungs, her muscular coordination, her nerves during such an effort, she thinks of it primarily not in terms of pain but of challenge. (p. 123)
}

A broader understanding of comfort in labor can cause a shift in the biomedical paradigm of need for epidural anesthetics and other types of medication during labor. Women may come to realize that other measures are supportive during the birth experience and may place the woman and her unborn child at less risk.

Perhaps by beginning to identify those measures that strengthen us during childbirth and which caregivers can use to enhance comfort in birth, women will recognize childbirth as a challenge to be met with expectations of mastery.

\section{References}

American College of Nurse-Midwives (1983). Philosophy. Fact Sheet. Washington, D.C.: Author.

Andrews, C., \& Chrzanowski, M. (1990). Maternal position, labor and comfort. Applied Nursing Research, 3, 7-13.

Cahill, C. (1989). Beta-endorphin levels during pregnancy and labor: A role in pain modulation? Nursing Research, 38, 200-203.

Cameron, B. (1993). The nature of comfort to hospitalized medical surgical patients. Journal of Advanced Nursing, 18, 424-430.

Cogan, R. (1975). Comfort during prepared childbirth as a function of parity, reported by four classes of participant observes. Journal of Psychomatic Research, 19, 33-37.

Collins, B., McCoy, S., Sale, S., \& Weber, S. (1994). Descriptions of comfort by substance-using and nonusing postpartum women. Journal of Obstetric, Gynecologic, and Neonatal Nursing, 23, 293-300. 
Davenport-Slack, B., \& Boylan, C. (1974). Psychological correlates of childbirth and pain. Psychosomatic Medicine, 36, 215.

Fridh, G., Kopare, T., Gaston-Johansson, F., \& Norvelle, K. (1988). Factors associated with more intense labor pain. Research in Nursing \& Health, 11, $117-124$

Funk, S., Tornquist, E., Champagne, M., Copp, L., \& Wiese, R., (Ed.). (1989). Key aspects of comfort: Management of pain, fatigue, and nausea. New York: Springer.

Gropper, E. (1992). Promoting health by promoting comfort. Nursing Forum, $27,5-8$.

Harmer, B. (1924). Textbook of the principles and practice of nursing. New York: MacMillan.

Hodnett, E. (1996). Nursing support of the laboring woman. JOGN, 25, 257-264 Jacox, A. (1989). Key aspects of comfort. In S. Funk, E. Tournquist, M. Champagne, L. Copp, \& R. Wiese, (Eds.), Key aspects of comfort: Management of pain, nausea and fatigue (1st ed., 8-21). New York: Springer Co.

Kelpin, V. (1984). Birthing pain. Phenomenology \& Pedagogy: A Human Science Journal, 2, 178-187.

Kolcaba, K. (1991). A taxonomic structure for the concept of comfort. Image: Journal for Nursing Scholarship, 23, 237-240.

Kolcaba, K. (1994). A theory of holistic comfort. Journal of Advanced Nursing, 19, 1178-1184.

Kolcaba, K. (1995a). The art of comfort care. Image: Journal of Nursing Scholarship, 27, 287-289.

Kolcaba, K. (1995b). Comfort as process and product, merged in holistic nursing art. Journal of Holistic Nursing, 13, 117-131.

Kuby, J. (1994). Immunology (2nd ed.). New York: W.H. Freeman.

Lowe, N. (1989). Explaining the pain of active labor: The importance of maternal confidence. Research in Nursing \& Health, 12, 237-245.

Lowe, N. (1991). Critical predictors of sensory and affective pain during four phases of labor. Journal of Psychosomatic Obstetrics \& Gynecology, 12 , 193-208.

Lowe, N. (1996). The pain and discomfort of labor and birth. Journal of Obstetrics, Gynecologic, and Neonatal Nursing, 25, 82-92.

\section{Barry University School of Nursing}

\section{GRADUATE FACULTY POSITIONS}

Family Nurse Practitloner Specialization. Applicants must possess doctorate in nursing or related field, and have (or be eligible for) dual license) certification as Advanced Nurse Practitioner in Florida. Recent clinical experience as nurse practitioner is expected and ongoing clinical practice is anticipated. Previous graduate teaching preferred along with evidence of scholarshio.

Other Teaching Positlons. Applicants with a doctorate in nursing or related field who are committed to participating in a community of scholars and are eligible for the senior ranks of associate and full professor are invited to apply.

Quallfications include: expertise in philosophy and science of nursing; expertise in qualitative and/or quantitative research; graduate level teaching experience; a record of scholarship and research based publications; and experience in mentoring research for master's and doctoral students

Submit curriculum vitae, transcripts, and three references to Judith Balcerski, RN, PhD; Dean; Barry University School of Nursing; 11300 NE Second Avenue Miami Shores, FL 33161.

Applications treated in confidence.

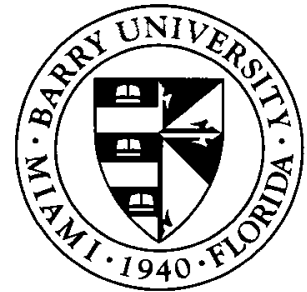

BARRY UNIYERSITY IS AN EQUAL OPPORTUNITY EMPLOYER.
Mander, R. (1992). The control of labor pain. Journal of Clinical Nursing, 1, 219-223.

Mcllveen, K., \& Morse, J. (1995). The role of comfort in nursing care: 19001980. Clinical Nursing Research, 4, 127-148.

Morse, J. (1983). An ethnoscientific analysis of comfort: A preliminary investigation. Nursing Papers, 15, 6-19.

Morse, J., Bottorff, J., \& Hutchinson, S. (1994). The phenomenology of comfort. Journal of Advanced Nursing Science, 20, 189-195.

Morse, J., Bottorff, J., \& Hutchinson, S. (1995). The paradox of comfort. Nursing Research, 44, 14-19.

Paterson, J., \& Zderad, L. (1988). Humanistic nursing (2nd ed.). New York: National League for Nursing.

Rich, A. (1976). Of woman born. New York: W. W. Norton.

Sampselle, C., \& Hines, S. (In Press). Pelvic floor exercise. In Press.

Simkin, P. (1995). Reducing pain and enhancing progress in labor: A guide to nonpharmacologic methods for maternity caregivers. Birth, 22, 161-171.

Stampone, D. (1990). The history of obstetric anesthesia. The Journal of Perinatal and Neonatal Nursing, 4, 1-13.

Stewart, A. (1994). Toward a feminist strategy for studying women's lives. In C. Franz \& A. Stewart (Eds.), Women creating lives (11-35). Boulder, CO: Westview Press.

Thompson, J., Oakley, D., Burke, M., Jay, S., \& Conklin, M. (1989). Theory building in nurse-midwifery. Journal of Nurse-Midwifery, 34, 120-130.

Van Blarcom, C. (1953). Obstetrical nursing (3rd ed.). New York: Macmillan.

Varney, H. (1997). Varney's Midwifery (3rd ed.). Boston: Jones \& Bartlett.

Walters, A. (1994). The comforting role in a critical care nursing practice: A phenomenological interpretation. International Journal of Nursing Studies, 6, 607-616

Weber, S. (1996). Cultural aspects of pain in childbearing women. Journal of Obstetrics, Gynecologic, and Neonatal Nursing, 25, 67-72.

Yerby, M. (1996). Managing pain in labor: Part I: perceptions of pain. Modern Midwife, 22-24.

Youngstrom, P., Baker, S., \& Miller, J. (1996). Epidurals redefined in analgesia and anesthesia: A distinction with a difference. Journal of Obstetrics, Gynecologic, and Neonatal Nursing, 25, 350-354.

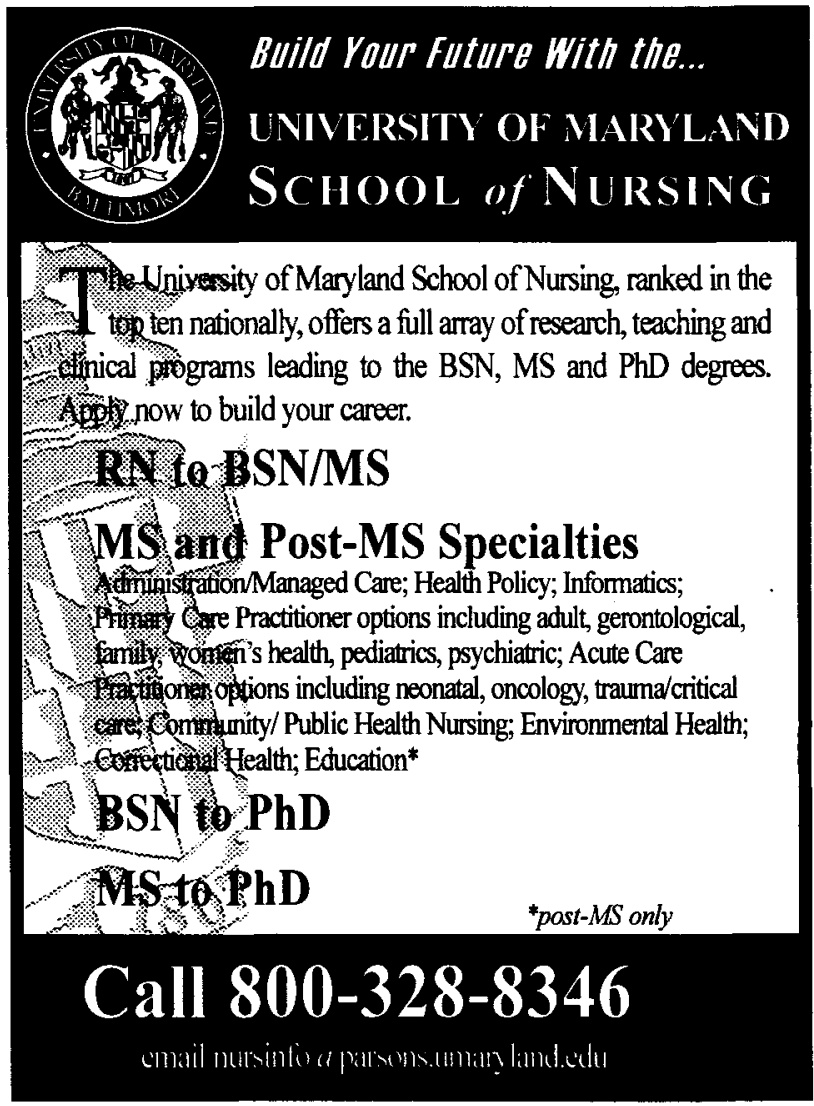




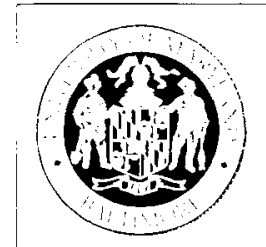

Build Your future with the...

UNIVIRSITY OF MARYLAND

SCHOOL of NURSING

\section{SENIOR RESEARCH SCIENTISTS ONCOLOGY}

The he University of Maryland School of Nursing is currently seeking senior research scientists in the area of oncology. With more than 1,500 students, the School of Nursing is consistently ranked among the top ten in the nation. Opportunities abound for research collaboration with faculty of the schools of Dentistry, Law, Medicine, Pharmacy and Social Work as well as with the University of Maryland Medical System, a 747 bed tertiary care facility, the Marlene and Stewart Greenebaum Cancer Center, the Baltimore Veteran's Affairs Medical Center and the world renowned Shock Trauma Center. The campus is recognized as a national leader in health sciences research with over $\$ 146$ million in grants and contracts in FY 98.

Qesponsibilities: Senior research scientists provide leadership in oncology research, secure external funding to support their research, teach in the graduate program, advise master's and doctoral students and mentor other faculty.

O ualifications: Requirements for the position of senior research scientist include an earned doctorate in nursing or a related field, a master's degree in nursing and a current license or eligibility to practice nursing in Maryland. Significant scholarly achievement including research publications, and a proven track record in peer reviewed and externally funded research, sufficient to qualify for appointment to the rank of associate professor or professor is also required. Prior academic experience is preferred.

Tnstructions to Applicants: Applicants should submit a letter of Linterest, resume and the names of three professional references to:

Faculty Search Committee clo Barbara R. Helle, EdD, RN, FAAN, Dean, University of Maryland School of Nursing 655 West Lombard Street, Room 725

Baltimore, Maryland 21201

The University of Maryland is an Equal Opportunity/Affirmative Action/ADA Employer.

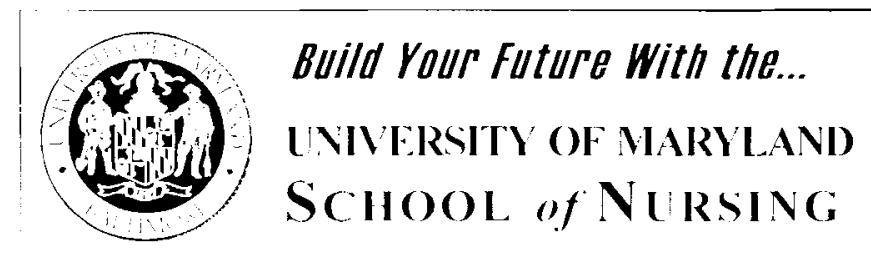

\section{ACUTE CARE NURSE PRACTITIONERS AND SENIOR RESEARCH FACULTY}

The University of Maryland School of Nursing is currently seeking acute care nurse practitioners and senior research faculty in the area of trauma/critical care. With more than 1,500 students, the School of Nursing is consistently ranked among the top ten in the nation. Opportunities abound for collaborative practice and research with faculty of the schools of Dentistry, Law, Medicine, Pharmacy and Social Work as well as with the University of Maryland Medical System, a 747 bed tertiary care facility, the Baltimore Veteran's Affairs Medical Center and the world renowned Shock Trauma Center. The campus is recognized as a national leader in health sciences research with over $\$ 146$ million in grants and contracts in FY 98 .

Desponsibilities: Acute care nurse practitioners teach in the Rschool's undergraduate and graduate programs, advise students and provide clinical services in operations managed by the School or in other healthcare facilities under School contracts. Senior research faculty provide leadership in their specialty area, secure external funding, teach in the academic programs, advise master's and doctoral students and participate in scholarly projects.

Uualifications: Nurse practitioners must hold a master's degree in nursing (doctorate in nursing or related field preferred), certification as a nurse practitioner and be eligible or currently licensed to practice nursing in Maryland. Senior research faculty must have an earned doctorate in nursing or a related field and current license or eligibility to practice nursing in Maryland. Significant scholarly achievements, including research publications and a proven track record in peer reviewed and externally funded research sufficient to qualify for appointment to the rank of associate professor or professor.

Tnstructions: Applicants should submit a letter of interest, Iresume and the names of three professional references to:

Faculty Search Committee

clo Barbara R Heller, EdD, RN, FAAN,

Dean, University of Maryland School of Nursing

655 West Lombard Street, Room 725

Baltimore, Maryland 21201

The Universiny of Marytand is an Equal Opportunity/Affirmative Action/ADA Employer. 